\title{
Validation of HPLC Method for the Determination of 17 $\alpha$-Ethynylestradiol (EE2) in Aqueous Phase
}

\author{
Lim Yee Ling, ${ }^{1}$ Norhashimah Morad,${ }^{1 *}$ Abbas F. M. Alkarkhi ${ }^{2}$ and Norli Ismail ${ }^{1}$ \\ ${ }^{1}$ Environmental Technology Division, School of Industrial Technology, \\ Universiti Sains Malaysia, 11800 USM Pulau Pinang, Malaysia \\ ${ }^{2}$ Malaysian Institute of Chemical and Bioengineering Technology, \\ Universiti Kuala Lumpur (UniKL-MICET), 78000 Alor Gajah, Melaka, Malaysia \\ *Corresponding author: nhashima@usm.my
}

Published online: 25 October 2018

To cite this article: Validation of HPLC method for the determination of 17 $\alpha$-ethynylestradiol (EE2) in aqueous phase. (2018). J. Phys. Sci., 29(Supp. 3), 87-94, https://doi.org/10.21315/jps2018.29.s3.11

To link to this article: https://doi.org/10.21315/jps2018.29.s3.11

\begin{abstract}
Significant impact of estrogen pollution in the ecological system has drawn the attention of researchers as estrogenic pollution causes the change in female gonadal phenotype, decrease in fertility and fish feminisation, that eventually lead to depopulation. Major sources of estrogenic pollution are hormone treatments and discharges of humans and animals. As vital as it is to investigate the presence of estrogenic pollution in water bodies, there is a lack of simple validated method to determine the level of estrogenic pollution in water bodies. The only determination method currently being used is highresolution gas chromatography/mass spectrometry (HRGC/HRMS) under the Clean Water Act. However, this method is not widely applied due to its unavailability in most common laboratories. Thus, this current research investigates and validates a rapid and accurate estimation of $17 \alpha$-ethynylestradiol (EE2) using a high-performance liquid chromatography (HPLC), an equipment commonly available in most research laboratories. This method validation is done in accordance with the guidelines for pharmaceutical drug detection, which include system suitability, system sensitivity, system linearity, accuracy and precision. The suitable wavelength of the HPLC was detected at $280 \mathrm{~nm}$, with the limit of detection and quantification at the differential height of $\triangle 0.0465 \mathrm{mAU}$ and $\triangle 0.1550 \mathrm{mAU}$ each. The accuracy and precision of the system were validated at coefficient of variance in the range of $0.01 \%$ to $0.09 \%$, which is much lower than the accepted value of $5 \%$. Lastly, the validation of system linearity gives a regression value of 0.9993. Thus, this method is deemed valid for the detection of EE2 in aqueous solution.
\end{abstract}

Keywords: $17 \alpha$-ethynylestradiol, estrogenic pollutions, high-performance liquid chromatography, method validation, HPLC validation 


\section{INTRODUCTION}

Impact of estrogenic compounds in water bodies to the aquatic living is undeniable. Adaptation of aquatic organisms to the exposure of estrogenic compounds by modifying their characteristics will eventually cause the whole ecosystem to wipe out. ${ }^{1-6}$ The sources of these estrogenic compounds are not limited to contraceptive pills and growth promoter, but also due to human and animal discharges that end up in sewage treatment plants, which is the cumulative centre for estrogenic pollutions. $^{6-9}$

Methods employed by researchers to determine the concentration of estrogens so far are high-performance liquid chromatography mass spectrometry (HPLC-MS), gas chromatography mass spectrometry (GC-MS) and vitro bio-assay. According to the United States Environmental Protection Agency (EPA) standard, highresolution GC combined with high-resolution mass spectrometry (HRGC/HRMS) is required for hormone identification under the Clean Water Act. This standard, however, is not employed by most researchers due to its unavailability in most research labs. Whereas, for HPLC, the standard method for the determination of $17 \alpha$-ethynylestradiol (EE2) is yet to be recorded.

In this research, HPLC and C-18 column commonly available in general laboratories are used. This research validates and determine the suitability of a rapid and accurate estimation of EE2 through a validated method of HPLC.

\section{EXPERIMENTAL}

Standard solutions are prepared by serial dilution, producing standard concentrations of $50.0 \mu \mathrm{g} \mathrm{ml}^{-1}, 10.0 \mu \mathrm{g} \mathrm{ml}^{-1}, 1.0 \mu \mathrm{g} \mathrm{ml}^{-1}, 0.5 \mu \mathrm{g} \mathrm{ml}^{-1}$ and $0.1 \mu \mathrm{g} \mathrm{ml}^{-1}$ for linearity test, using a stock solution of $1000 \mu \mathrm{g} \mathrm{ml}^{-1}$, prepared from $98 \%$ purity EE2 from Sigma Aldrich. Each replicate for standard solution is prepared from the initial EE2 to minimise human error during the dilution process.

HPLC 1260 Infinity Series with Column Zobrax SB-C18 by Agilent Technologies is used for the entire research project. Acetonitrile and deionised water, which is the carrier for the column is used at a ratio of 45:55. The flow rate of the HPLC instrument is adjusted to $1 \mathrm{ml} \mathrm{min}^{-1}$, at a temperature of $30^{\circ} \mathrm{C}$, and injection volume of $90 \mu 1$ are used. These selected conditions are modified from Sigma Aldrich application report for Waters system. ${ }^{10}$ 
To ensure an accurate quantitation in the research, a series of method validation procedure must be conducted. ${ }^{11}$ First, the system suitability at different wavelengths: two concentrations representing a low concentration at $2 \mu \mathrm{g} \mathrm{ml}^{-1}$ and a high concentration of $100 \mu \mathrm{g} \mathrm{ml}^{-1}$ are applied to the HPLC with a series of wavelength ranging from $200 \mathrm{~nm}$ to $340 \mathrm{~nm}$ with six replicates. Next, the system sensitivity is determined by the limit of detection (LOD) and limit of quantitation (LOQ). An evaluation based on a signal-to-noise ratio is employed for this study; the system is validated when baseline noise and the limit of detection is at a signal-to-noise ratio of 3 or $2: 1 .^{11,12}$ The lowest concentration in the study range of $0.1 \mu \mathrm{g} \mathrm{ml}^{-1}$ is used to gauge the system sensitivity.

The accuracy and precision in this experiment are evaluated by determining the intra-day variations and inter-day variations with a total of six replicates at different concentration. Finally, system linearity or the calibration curve is determined based on a procedure that runs on a range of known concentration to obtain an unknown result with direct proportion to the linearity. The linearity of this system is evaluated by running a set of concentrations of EE2 at $0.1 \mu \mathrm{g} \mathrm{ml}^{-1}, 0.5 \mu \mathrm{g} \mathrm{ml}^{-1}$, $1.0 \mu \mathrm{g} \mathrm{ml}^{-1}, 10.0 \mu \mathrm{g} \mathrm{ml}^{-1}, 50.0 \mu \mathrm{g} \mathrm{ml}^{-1}$ and $100 \mu \mathrm{g} \mathrm{ml}^{-1}$ at a total of six points with three replicates.

\section{RESULTS AND DISCUSSION}

\subsection{Determination of System Suitability at Different Wavelengths}

The range of wavelength studied for the adsorption of EE2 is $200 \mathrm{~nm}$ to $340 \mathrm{~nm}$. Although the highest adsorption reading is obtained from wavelength at $200 \mathrm{~nm}$, this wavelength is not employed in this experiment as the UV cut-off point for acetonitrile and deionised water is at $190 \mathrm{~nm}$, and a wavelength of $200 \mathrm{~nm}$ is considered too close to this value. Thus, wavelength $280 \mathrm{~nm}$ is adopted as it is the only wavelength that produces a smooth and complete peak. In addition, the retention time is found to be $12.53 \pm 0.2 \mathrm{~min}$ for overall retention time ranging from low concentration of $2 \mu \mathrm{g} \mathrm{ml}^{-1}$ to high concentration of $100 \mu \mathrm{g} \mathrm{ml}^{-1}$, to ensure the validity of the reading obtained.

Furthermore, the relative standard deviation (\%RSD) obtained at a wavelength of $200 \mathrm{~nm}$ for low concentration is $3.61 \%$, while $220 \mathrm{~nm}$ is $6.00 \%$ in contrast to $1.43 \%$ obtained at a wavelength of $280 \mathrm{~nm}$ from six replicates as shown in Table 1. Although all three wavelengths give $\%$ RSD of less than $0.5 \%$ at high concentration, $\%$ RSD for $200 \mathrm{~nm}$ and $220 \mathrm{~nm}$ are unable to fulfill the requirement 
of method suitability (of less than $2 \%$ ) at low concentration as listed in Table $1 .{ }^{12}$ Thus, the wavelength of $280 \mathrm{~nm}$ is selected to be used throughout the EE2 analysis.

Table 1: Relative standard deviation for $n=6$.

\begin{tabular}{lccc}
\hline Concentration $2 \mu \mathrm{g} \mathrm{ml}^{-1}$ (low concentration) & & \\
\hline Wavelength & 200 & 220 & 280 \\
Replicate 1 & 2.32 & 2.35 & 2.21 \\
Replicate 2 & 2.15 & 2.11 & 2.28 \\
Replicate 3 & 2.39 & 2.49 & 2.28 \\
Replicate 4 & 2.34 & 2.49 & 2.28 \\
Replicate 5 & 2.26 & 2.26 & 2.21 \\
Replicate 6 & 2.21 & 2.21 & 2.21 \\
Mean & 2.28 & 2.32 & 2.24 \\
\%RSD & 3.61 & 6.00 & 1.43 \\
\hline Concentration 100 $\mu \mathrm{g} \mathrm{ml} l^{-1}$ (high concentration) & \\
\hline Wavelength (nm) & 200 & 220 & 280 \\
Replicate 1 & 112.45 & 112.59 & 112.11 \\
Replicate 2 & 112.12 & 111.93 & 112.36 \\
Replicate 3 & 111.76 & 111.61 & 112.08 \\
Replicate 4 & 111.54 & 111.50 & 111.76 \\
Replicate 5 & 111.39 & 111.45 & 111.27 \\
Replicate 6 & 111.39 & 111.45 & 111.69 \\
Mean & 111.78 & 111.75 & 111.88 \\
\%RSD & 0.35 & 0.36 & 0.31 \\
\hline
\end{tabular}

\subsection{System Sensitivity: Limit of Detection and Quantitation}

The differential height obtained for the baseline noise is $\Delta 0.0155 \mathrm{mAU}$. For LOD, the signal to noise ratio is set to $3: 1$, which is three folds the height of baseline noise, whereby any reading recorded with the differential height of $\Delta 0.0465 \mathrm{mAU}$ or above is acceptable. Whereas for LOQ, a ratio of 10:1 which is 10 folds the height of the baseline noise is employed. The acceptable differential height for LOD and LOQ can be seen in Table 2 . 
Table 2: LOD and LOQ for the system based on signal to noise ratio.

\begin{tabular}{lcc}
\hline & Signal to noise ratio & Accepted height \\
\hline Baseline noise & $3: 1$ & $\Delta 0.0155 \mathrm{mAU}$ \\
LOD & $10: 1$ & $\Delta 0.0465 \mathrm{mAU}$ \\
LOQ & $\Delta 0.1550 \mathrm{mAU}$ \\
\hline
\end{tabular}

For further assurance of the system sensitivity and the validity of data recorded, Figure 1 indicates $0.1 \mu \mathrm{g} \mathrm{ml}{ }^{-1}$ concentration of EE2 which is the lowest point of the calibration curve. The height obtained from the graph is $0.17 \mathrm{mAU}$ which is still considered as a higher reading compared to the limit of quantitation which requires only $\Delta 0.1550 \mathrm{mAU}$ in height. Comparing the lowest possible reading in the experimental runs and both the accepted height for the LOD which is $\Delta 0.0465 \mathrm{mAU}$, and LOQ which is $\Delta 0.1550 \mathrm{mAU}$, all the recorded data in this research is deemed valid and in the acceptable range required in this method validation.

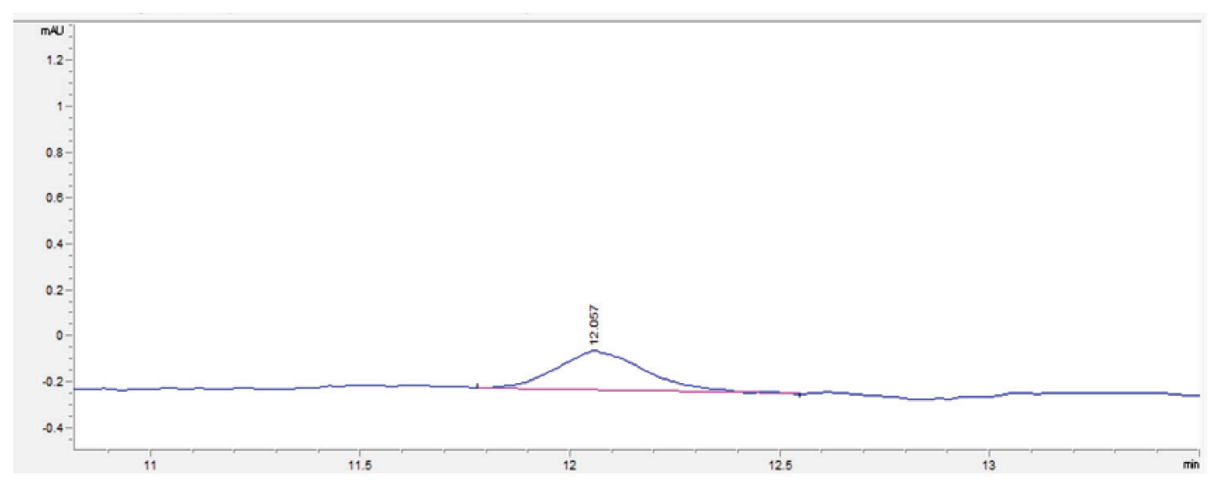

Figure 1: Concentration of EE2 at $0.1 \mu \mathrm{g} \mathrm{ml}^{-1}$.

\subsection{Accuracy and Precision}

The accuracy and precision of the method are obtained from the intra and inter-day study as given in Table 3. The intra-day readings show standard deviations in the range of 0.05 to 0.16 . The precision of the method is determined by the coefficient of variance reading, which is in the range of $0.01 \%$ to $0.09 \%$. A good precision is also obtained from the intermediate precision, which is the inter-day precision value. Since all the coefficient of variance obtained from the intra-day and interday variations are much lower value than the accepted value of 5\%, this method is considered to be meeting the requirement for system accuracy and precision testing. 
Table 3: Intra and inter-day accuracy and precision study.

\begin{tabular}{ccccc}
\hline Day & $\begin{array}{c}\text { Concentration } \\
\left(\mu \mathrm{g} \mathrm{ml}^{-1}\right)\end{array}$ & Mean $\left(\mu \mathrm{g} \mathrm{ml}^{-1}\right)$ & Standard deviation & $\begin{array}{c}\text { Coefficient of } \\
\text { variance }(\%)\end{array}$ \\
\hline \multirow{3}{*}{1} & 0.5 & 0.52 & 0.05 & 0.09 \\
& 5.0 & 5.44 & 0.16 & 0.03 \\
& 10.0 & 11.04 & 0.12 & 0.01 \\
\hline & 0.5 & 0.54 & 0.02 & 0.03 \\
& 5.0 & 5.47 & 0.11 & 0.02 \\
& 10.0 & 11.02 & 0.12 & 0.01 \\
\hline & 0.5 & 0.53 & 0.01 & 0.03 \\
& 5.0 & 5.41 & 0.13 & 0.02 \\
& 10.0 & 11.00 & 0.13 & 0.01 \\
\hline
\end{tabular}

\subsection{Detection Linearity (Calibration Curve)}

A calibration curve is plotted for this experimental run based on the concentration of EE2 within the range of 0.1 to $100.0 \mu \mathrm{g} \mathrm{ml}^{-1}$, with a total of six points. The detection wavelength is fixed at $280 \mathrm{~nm}$. The regression coefficient, $\mathrm{R}^{2}$ obtained from this standard curve is 0.9993 and the slope is found to be 3.226 giving the regression equation at $\mathrm{y}=3.226 \mathrm{x}$. This system linearly is valid as the $\mathrm{R}^{2}$ obtained is above the value of 0.95 . Thus, the calibration curve is deemed suitable to be used throughout the whole research for data collection.

\section{CONCLUSION}

An EE2 detection method is validated using HPLC for the range of EE2 from $0.1 \mu \mathrm{g} \mathrm{ml}^{-1}$ to $100.0 \mu \mathrm{g} \mathrm{ml}^{-1}$. A suitable wavelength was identified at $280 \mathrm{~nm}$ with the retention time at $12.53 \pm 0.2 \mathrm{~min}$. Based on the limit of detection and limit of quantification of the system, all data recorded is valid and bound within the range. The accuracy and precision of the method studied with the EE2 compound are found to be acceptable given the coefficient of variations is all below $5 \%$. Lastly, the detection of linearity gives a standard curve of 0.9993 regression value, validating the equation found at $\mathrm{y}=3.226 \mathrm{x}$ where $\mathrm{y}$ is the detection area in HPLC and $\mathrm{x}$ is the unknown EE2 concentration. 


\section{ACKNOWLEDGEMENTS}

The authors gratefully acknowledge financial support from Universiti Sains Malaysia in the form of postgraduate fellowship as well as Research University grant 1001/PTEKIND/814138, which have resulted in this publication. The authors also acknowledge support and advice from the research staff and fellow postgraduate students during the course of this work.

\section{REFERENCES}

1. Doyle, C. J. \& Lim, R. P. (2002). The effect of $17 \beta$-estradiol on the gonopodial development and sexual activity of Gamb. Holbr. Environ. Toxicol. Chem., 21(12), 2719-2724, https://doi.org/10.1002/etc.5620211227.

2. Tashiro, Y. et al. (2003). Livestock wastes as a source of estrogens and their effects on wildlife of Manko tidal flat, Okinawa. Mar. Pollut. Bull., 47(1-6), 143-147, https://doi.org/10.1016/S0025-326X(03)00053-5.

3. Woodling, J. D. et al. (2006). Intersex and other reproductive disruption of fish in wastewater effluent dominated Colorado streams. Compar. Biochem. Phys. C Toxicol. Pharmacol., 144(1), 10-15, https://doi.org/10.1016/j. cbpc.2006.04.019.

4. Thompson, M. L. et al. (2009). Occurrence and pathways of manure-borne 17[beta]-estradiol in vadose zone water. Chemosph., 76(4), 472-479, https:// doi.org/10.1016/j.chemosphere.2009.03.037.

5. Ying, G. G. et al. (2009). Occurrence and implications of estrogens and xenoestrogens in sewage effluents and receiving waters from South East Queensland. Sci. Total Environ., 407(18), 5147-5155, https://doi. org/10.1016/j.scitotenv.2009.06.002.

6. Duong, C. N. et al. (2010). Estrogenic chemicals and estrogenicity in river waters of South Korea and seven Asian countries. Chemosph., 78(3), 286293, https://doi.org/10.1016/j.chemosphere.2009.10.048.

7. Ying, G. G., Kookana, R. S. \& Ru, Y.-J. (2002). Occurrence and fate of hormone steroids in the environment. Environ. Int., 28(6), 545-551, https:// doi.org/10.1016/S0160-4120(02)00075-2.

8. Ivanov, V. et al. (2010). Biodegradation of estrogens by facultative anaerobic iron-reducing bacteria. Process Biochem., 45(2), 284-287, https://doi. org/10.1016/j.procbio.2009.09.017.

9. Sim, W. J. et al. (2011). Assessment of fates of estrogens in wastewater and sludge from various types of wastewater treatment plants. Chemosph., 82(10),1448-1453, https://doi.org/10.1016/j.chemosphere.2010.11.045.

10. Cramer, H. (2004). Application report 84. New York: Sigma Aldrich. 
11. ICH Expert Working Group. (2005). Validation of analytical procedures: Text and methodology Q2 (R1). Paper presented at the Proceedings of the International Conference on Harmonisation of Technical Requirements for Registration of Pharmaceuticals for Human Use, 25-27.

12. Sistla, R. et al. (2005). Development and validation of a reversed-phase HPLC method for the determination of ezetimibe in pharmaceutical dosage forms. J. Pharm. Biomed. Anal., 39(3-4), 517-522, https://doi.org/10.1016/j. jpba.2005.04.026. 